\title{
From array-based hybridization of Helicobacter pylori isolates to the complete genome sequence of an isolate associated with MALT lymphoma
}

\author{
Jean-Michel Thiberge1, Caroline Boursaux-Eude2, Philippe Lehours 3 , Marie-Agnès Dillies 4 , Sophie Creno5, Jean- \\ Yves Coppée ${ }^{4}$, Zoé Rouy ${ }^{6}$, Aurélie Lajus ${ }^{6}$, Laurence Ma5 ${ }^{5}$, Christophe Burucoa7, Anne Ruskoné-Foumestraux \\ Anne Courillon-Mallet ${ }^{9}$, Hilde De Reuse ${ }^{10}$, Ivo Gomperts Boneca11,12, Dominique Lamarque ${ }^{13}$, Francis Mégraud ${ }^{3}$, \\ Jean-Charles Delchier ${ }^{14}$, Claudine Médigue ${ }^{6}$, Christiane Bouchier ${ }^{5}$, Agnès Labigne ${ }^{10}$ and Josette Raymond*10,15
}

\begin{abstract}
Background: elicobacter pylori infection is associated with several gastro-duodenal inflammatory diseases of various levels of severity. To determine whether certain combinations of genetic markers can be used to predict the clinical source of the infection, we analyzed well documented and geographically homogenous clinical isolates using a comparative genomics approach.

Results: A set of $254 \mathrm{H}$. pylori genes was used to perform array-based comparative genomic hybridization among 120 French H. pylori strains associated with chronic gastritis $(n=33)$, duodenal ulcers $(n=27)$, intestinal metaplasia $(n=17)$ or gastric extra-nodal marginal zone B-cell MALT lymphoma $(n=43)$. Hierarchical cluster analyses of the DNA hybridization values allowed us to identify a homogeneous subpopulation of strains that clustered exclusively with cagPAI minus MALT lymphoma isolates. The genome sequence of B38, a representative of this MALT lymphoma straincluster, was completed, fully annotated, and compared with the six previously released H. pylori genomes (i.e. J99, 26695, HPAG1, P12, G27 and Shi470). B38 has the smallest H. pylori genome described thus far (1,576,758 base pairs containing 1,528 CDSs); it contains the vacAs $2 \mathrm{~m} 2$ allele and lacks the genes encoding the major virulence factors (absence of cagPAl, babB, babC, sabB, and homB). Comparative genomics led to the identification of very few sequences that are unique to the B38 strain (9 intact CDSs and 7 pseudogenes). Pair-wise genomic synteny comparisons between B38 and the 6 H. pylori sequenced genomes revealed an almost complete co-linearity, never seen before between the genomes of strain Shi470 (a Peruvian isolate) and B38.
\end{abstract}

Conclusion: These isolates are deprived of the main H. pylori virulence factors characterized previously, but are nonetheless associated with gastric neoplasia.

\section{Background}

Helicobacter pylori infections occur in approximately $50 \%$ of the human population and are associated with several inflammatory gastroduodenal diseases [1], including two types of gastric cancers: gastric adenocarcinoma [2] and gastric extra-nodal marginal zone B-cell MALT (mucosaassociated lymphoid tissue) lymphoma, first described by Isaacson et al. [3]. Evolution of this bacterial infection

\footnotetext{
*Correspondence: josette.raymond@cch.aphp.fr

10 Institut Pasteur, Unité postulante de Pathogenèse de Helicobacter, Paris, France

Full list of author information is available at the end of the article
}

towards malignancy only occurs in approximately $1 \%$ of infected individuals, suggesting that both bacterial and host susceptibility factors are involved[4].

Since the discovery of $H$. pylori, several studies have focused on elucidating $H$. pylori pathogenicity mechanisms (microbial factors) that are associated with disease outcomes[5]. The cag-pathogenicity island (cagPAI) has been recognized as a major pro-inflammatory actor, but its association with MALT lymphoma strains has yet to be clearly shown [6]. The VacA vacuolating cytotoxin, thought to cause detectable alterations in gastric epithelial cells and immune cells, is also one of the most studied 
H. pylori virulence factors [7]. VacA has also been suggested to play a role in $H$. pylori persistence, demonstrated by in vitro studies, based on its immunosuppressive properties [8]. Adhesion of H. pylori to gastric epithelial cells is another bacterial trait contributing to chronic state of the infection. BabA [9], SabA [10], HopZ [11], HomB [12] and 30 outer-membrane-like paralogs recognized as adhesins or potential adhesins are encoded by the H. pylori genome [13]. Several studies have highlighted their contribution to pathogen fitness in human populations $[14,15]$. Over the last twenty years, genes encoding these virulence factors have served as genotyping markers to establish correlations between these markers, alone or in combination, and clinical outcomes of $H$. pylori infections [16].

Few studies have been conducted in relation to gastric MALT lymphoma-associated strains. Koehler et al. reported that the $v a c A \mathrm{~m} 2$ allele predominated in MALT lymphoma-associated isolates [17]. In previous studies $[18,19]$ including an identical collection of $H$. pylori gastric MALT lymphoma strains to that used here, the authors confirmed this finding and suggested that certain combinations of genomic markers may have a predictive value for determining whether gastric MALT lymphoma develops. All these data suggest the potential role for bacterial determinism in the clinical outcome of MALT lymphoma.

So far, comparative genomics involving sequenced $H$. pylori genomes have been limited to five clinical isolates isolated in the West and associated with gastritis [strain 26695 [20], peptic ulcers (strains J99 [GenBank:AE001439.1], P12 [EMBL:CP001217, EMBL:CP001218]), atrophic gastritis (HPAG1 [21]), or no known disease (strains G27 [22] and Shi470 [RefSeq:NC_010698]. However, no genome sequence of a $H$. pylori strain isolated from MALT lymphoma is currently available. Comparative genomics based on DNA-array analyses, first conducted by Salama et al. on 15 Caucasian isolates [23], led to the elucidation of the H. pylori core genome comprising the pool of ubiquitous $H$. pylori genes and strain-specific genes (non-ubiquitous). Gressmann et al. studied gene gain and loss during evolution, by comparing the genome of 56 globally representative strains of $\mathrm{H}$. pylori; they reported that $25 \%$ of the genes were non-ubiquitous [24]. Through comparative genomics based on the analysis of 24 clinical isolates from various geographical origins (Western, Asian, African countries) using whole genome DNA arrays, we identified 213 non-ubiquitous or strain-specific genes [25]. In this study, we describe the gene distribution of these 213 non-ubiquitous genes (Additional file 1) within genomes from a large geographically homogeneous French collection of 120 well-characterized $H$. pylori strains associated with chronic gastritis, duodenal ulcer, intestinal metapla- sia or gastric MALT lymphoma. A hierarchical clustering analysis of the DNA hybridization values identified a homogeneous phylogenic subpopulation of strains containing all of the cagPAI minus MALT lymphoma isolates. The B38 isolate was selected as a representative of this MALT lymphoma-specific cluster. Its genome sequence was completed, fully annotated, and compared with previously sequenced and published $H$. pylori genomes.

\section{Results and Discussion \\ Non-ubiquitous gene distribution in relation to associated diseases}

Hybridization results for the 120 studied DNAs used as a probe and the home-made macroarrays derived from the reference strain 26695 are presented in Additional file 1 (data based on the binary presence/absence analyses) and Figure 1 (data based on the multidimensional analysis of continuous values, see material and methods). Both presentations illustrate the distribution of each of the 254 genes (213 non-ubiquitous, and 41 ubiquitous, used for normalization) with respect to associated diseases. Each strain hybridization profile (Figure 1) is represented by a series of vertically aligned bar charts, whereas the horizontal lines represent each of the 254 genes. Each strain exhibited a unique profile. The most striking features were related to the distribution of the cagPAI genes: almost all $H$. pylori strains associated with metaplasia harbored a complete cagPAI, a result consistent with findings by Nilsson et al. [26]. However, a complete cagPAI was present in $70 \%$ of duodenal ulcer strains, and in $50 \%$ of chronic gastritis and of MALT lymphoma strains, confirming previously published findings for isolates collected in the West [27].

Hierarchical clustering of the continuous values derived from the hybridization experiments of 120 French clinical isolates presenting different disease characteristics was performed (Figure 1). This allowed us to visualize a branch clustering almost exclusively isolates associated with MALT lymphoma. Furthermore, principal component analysis allowed us to identify a combination of 48 genes (Additional file 1), which proved to be the most informative during multidimensional analysis. We then performed hierarchical clustering based on the values of these 48 genes (Figure 2). Two main branches were detected, one consisting of a distinct cluster of 20 isolates, all totally deprived of the cagPAI. Eighteen of the isolates were associated with MALT lymphoma and two with gastritis. Interestingly, none of the peptic ulcer or metaplasia isolates clustered in this branch. The second branch splits into two main clusters, one corresponding to isolates that totally or partially lack cagPAI genes mostly associated with gastritis and the other clustering isolates associated with other diseases. 


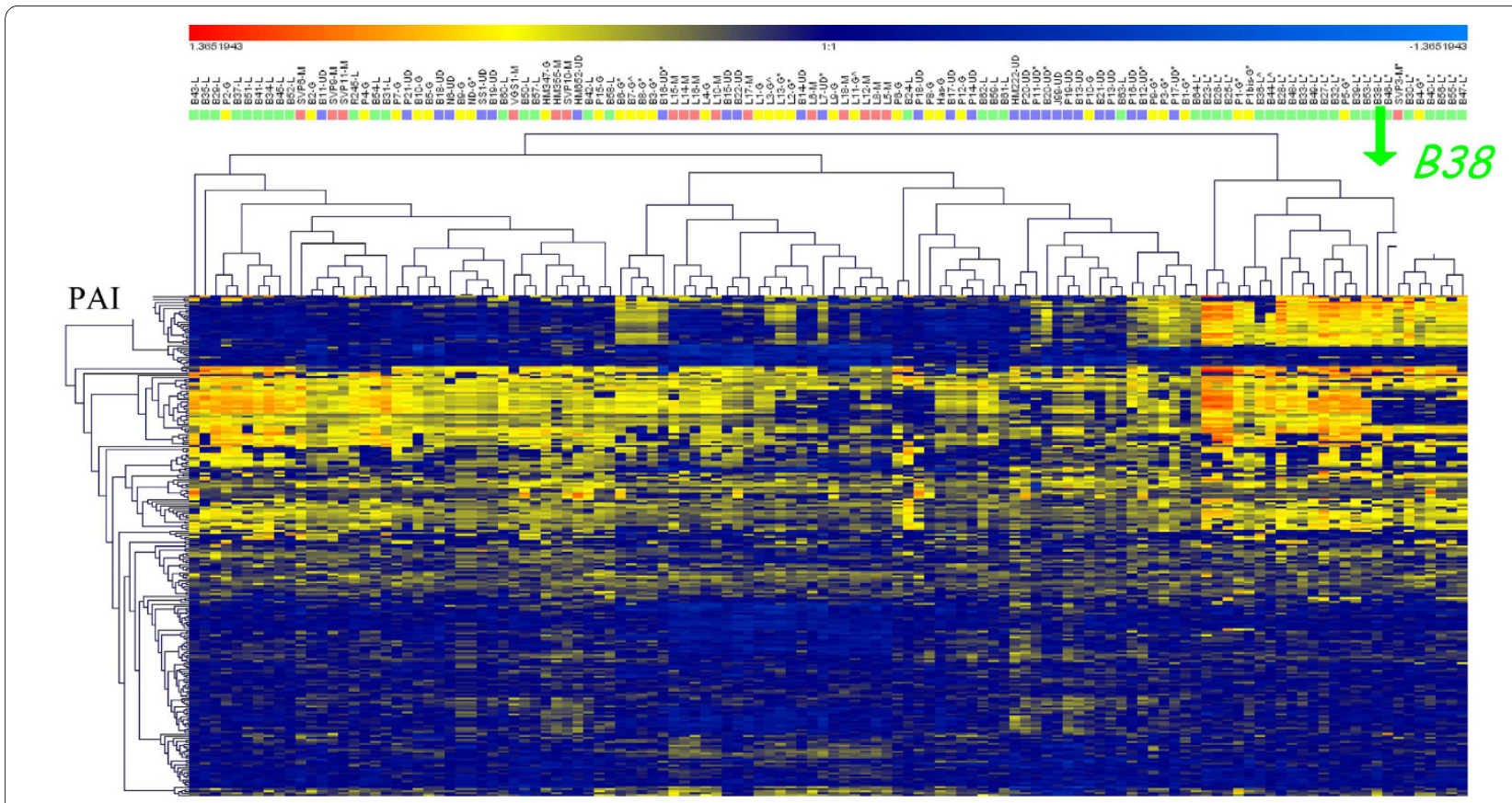

Figure 1 Hybridization reactions on a DNA macroarray membrane containing 254 PCR products that are representative of $H$. pylori strain 26695 (41 ubiquitous genes $+\mathbf{2 1 3}$ non-ubiquitous or strain-specific genes). Bacterial DNAs from 120 isolates involved in various diseases, including chronic gastritis (yellow), intestinal metaplasia (pink), duodenal ulcer (blue) and gastric MZBL (green), were tested by hybridization. Isolates are listed on the horizontal axis, and the genes tested, on the vertical axis. Clustering (genesis software) was carried out using the continuous values from 120 heterologous hybridization experiments, where each value corresponds to the $\left(\log _{26695}-\log _{\text {heterol.strain }}\right.$ ) value for each tested gene (see materials \& methods). Colors of the line range from blue, if the gene is present, to red, if absent. The range of intermediate colors reflects the degree of hybridization and thus homology, but also the redundancy of the tested genes. This figure represents the clustering based on the complete set of 254 genes.

To clarify the genetic determinism of the MALT lymphoma strains, we selected one strain that was representative of the MALT lymphoma cagPAI minus branch and determined its genome sequence. We selected strain B38, which was isolated from a 62-year-old man suffering from MALT lymphoma. It fulfilled various requirements: i) it belonged to the hpEurope phylogenetic branch according to MLST analysis (Suerbaum, personal communication), a property that was consistent with the five Helicobacter genome sequences previously published

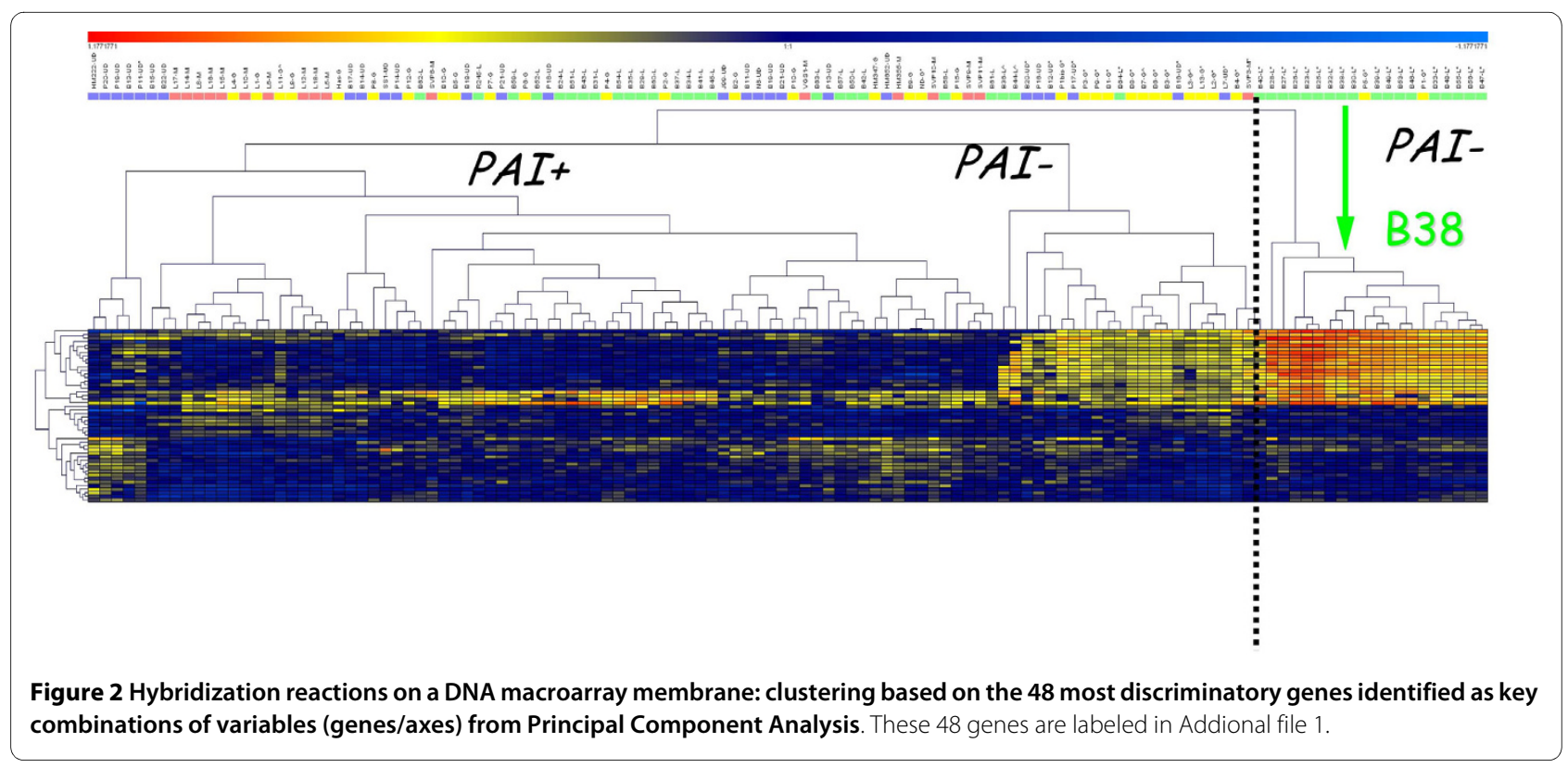


Table 1: Summary of comparative features of Helicobacter genomes

\begin{tabular}{|c|c|c|c|c|c|c|c|c|c|}
\hline Features of the strains & B38 & 26695 & $J 99$ & HPAG1a & Shi470 & G27a & P12a & $\begin{array}{l}\text { H. a Strain } \\
\text { Sheeba }\end{array}$ & $\begin{array}{c}\text { H. h Strain } \\
\text { ATCC } 51449\end{array}$ \\
\hline cagPAl & NEG & POS & POS & POS & POS & POS & POS & $\mathrm{HacGl}$ & HHGI1 \\
\hline Size (bp) & $1,576,758$ & $1,667,867$ & $1,643,831$ & $1,596,366$ & $1,608,547$ & $1,652,982$ & $1,673,813$ & $1,553,927$ & $1,799,146$ \\
\hline$(\mathrm{G}+\mathrm{C})$ content $(\%)$ & 39.2 & 38.9 & 39.2 & 39.1 & 38.9 & 38.9 & 38.8 & 38.2 & 35.9 \\
\hline Total CDSs $(n b)^{b}$ & 1,528 & 1,637 & 1,543 & 1,539 & 1,592 & 1,611 & 1,639 & 1,696 & 1,851 \\
\hline Complete CDSs $(n b)^{b}$ & 1,393 & 1,501 & 1,446 & 1,441 & 1,473 & 1,469 & 1,505 & 1,397 & 1,824 \\
\hline Average length $(\mathrm{bp})^{\mathrm{b}}$ & 971 & 964 & 988 & 971 & 955 & 954 & 957 & 933 & 914 \\
\hline Coding density (\%) $)^{b}$ & 85.0 & 86.3 & 86.6 & 87.3 & 87.2 & 84.6 & 85.8 & 83.6 & 92.3 \\
\hline Partial CDSs (nb) ${ }^{b}$ & 135 & 136 & 97 & 98 & 119 & 142 & 134 & 299 & 27 \\
\hline Truncated genes $(n b)^{b}$ & 2 & 9 & 10 & 7 & 4 & 7 & 7 & 11 & 11 \\
\hline Pseudogenes $(\mathrm{nb})^{\mathrm{b}}$ & $133(8.7 \%)^{c}$ & $127(7.8 \%)$ & $87(5.6 \%)$ & $91(5.9 \%)$ & $115(7.2 \%)$ & $135(8.4 \%)$ & $127(7.8 \%)$ & $288(17 \%)$ & $16(0.9 \%)$ \\
\hline $\begin{array}{l}\text { Fragmented } \\
\text { pseudogenes }(n b)^{b}\end{array}$ & $62(4 \%)^{d}$ & $61(3.7 \%)$ & $38(2.8 \%)$ & $43(2.8 \%)$ & $52(3.2 \%)$ & $64(3.9 \%)$ & $56(3.4 \%)$ & $81(4.8 \%)$ & $8(0.4 \%)$ \\
\hline tRNA (nb) & 36 & 36 & 36 & 36 & 36 & 36 & 36 & 36 & 37 \\
\hline \multicolumn{10}{|l|}{ Ribosomal RNA genes } \\
\hline $23 S(n b)$ & 2 & 2 & 2 & 2 & 2 & 2 & 2 & 2 & 1 \\
\hline $16 S(n b)$ & 2 & 2 & 2 & 2 & 2 & 2 & 2 & 2 & 1 \\
\hline $5 S(n b)$ & 3 & 3 & 2 & 2 & 2 & 3 & 2 & 2 & 1 \\
\hline $\begin{array}{l}\text { IS-types } \\
\text { (ORFs number) }\end{array}$ & $\begin{array}{l}\text { 20ISHp609 } \\
\text { (5) }\end{array}$ & $\begin{array}{c}17 \\
\text { IS606 } \\
\text { (1) IS605 } \\
\text { (5) IS200 (1) }\end{array}$ & $\begin{array}{c}6 \\
\text { IS606 } \\
\text { (1 remnant) } \\
\text { ISHp609 } \\
\text { (1 remnant) }\end{array}$ & $\begin{array}{c}7 \\
\text { IS606 } \\
\text { (2 remnant) } \\
\text { ISHp609 (1) }\end{array}$ & $\begin{array}{c}5 \\
\text { IS606 } \\
\text { in } 3 \text { fragments }\end{array}$ & $\begin{array}{c}9 \\
\text { IS605 (4) }\end{array}$ & 1 & $\begin{array}{c}13 \\
\text { ISHa1152 (2) } \\
\text { ISHa1942(1) } \\
\text { ISHa1675 (1) }\end{array}$ & $\begin{array}{l}\text { 21SHp609 } \\
\text { (1 remnant) }\end{array}$ \\
\hline
\end{tabular}


(26695, J99, HPAG1, P12, and G27); ii) it was genetically transformable; iii) it was plasmid free, and iv) it was capable of colonizing the mouse gastric mucosa. Its vacA status was s2m2 [18].

\section{Main features of the B38 genome}

The genome of the B38 strain consists of a circular chromosome containing 1,576,758 base pairs (bp) and an average GC content of $39.2 \%$ (Figure 3 ). It is the smallest H. pylori genome sequenced to date (Table 1). The B38 genome sequence was first automatically and then manually annotated using the MaGe system [28] http:// www.genoscope.cns.fr/agc/mage and was then compared with the other sequenced $H$. pylori genomes. It contains $1,528 \mathrm{CDSs}$ with a coding density $(85.0 \%)$ similar to that found in the other Helicobacter sequenced strains. Among the 1528 CDSs, 1393 were predicted to be protein-coding genes (complete CDSs) with an average length of $971 \mathrm{bp} ; 135$ correspond to partial CDSs, of which 133 are pseudogenes (i.e. 133 fragments representing 62 genes) and two are remnant genes (corresponding to truncated genes for which we cannot find the missing sections in close proximity) (Table 1).

Of the 1,528 annotated CDSs, a function was assigned to 989 CDSs (64.7\%). For 784 of them (79.3\%), a function was experimentally demonstrated either in the Helicobacter species $(188,12.3 \%)$ or in another organism (596, $39 \%)$. Two hundred and five CDSs (20.7\% of 989) received a function based on the presence of a conserved amino acid motif, a structural feature, or limited homology. A total of 378 CDSs have homologs in previously reported sequences of the genus Helicobacter (43.6\% of 378), in the epsilon proteobacteria (35.2\% of 378 ), or in other distant bacteria (21.2\% of 378). Protein function classification based on the cluster orthologous genes classification (COG) database allowed us to place 1189 of the 1528 CDSs $(77.81 \%)$ in at least one of the COG functional groups (Table 2): 454 were assigned to cellular processes and signaling systems, 342 to information storage and processing, while 595 were involved in metabolism. The B38 genome exhibits the highest percentage of CDSs associated with a COG group $(77.97 \%$ vs $73.38 \%$ for 26695, 76.48\% for J99, 76.15\% for HPAG1 and, 73.49 for Shi470), with the number of CDSs involved in defense mechanisms slightly higher than in the other sequenced Helicobacter strains.

There are a significant number of restriction/modification systems present in H. pylori; their composition and activity have been shown to be strain-specific [29]. In the B38 strain, 63 CDSs were involved in restriction/modification systems. Among them, 30 elements were fragmented into pseudogenes corresponding to 12 potential genes, and three elements appeared to be partial genes (Additional file 2). Thus, the proportion of potentially active genes (52\%) appeared to be higher in B38 than in strains J99 and 26695, in which only $30 \%$ of type II R-M systems were reported to be functional [30].

The B38 genome harbors five complete copies of the four-gene insertion sequence ISHp609. This insertion sequence was frequently found in $H$. pylori strains from Europe, Americas, India and Africa, but was almost always absent in strains from East Asia [31]. Three of the four genes (orf1, orf2, ORFA) demonstrated 100\% of identity in the five B38 ISHp 609 copies, whereas ORFB from one of the five B38 ISHp609 copies (HELPY1334) exhibited a single mutation. Among the sequenced genomes (Table 1), a single and complete copy of this element was found in strain HPAG1, but it differed slightly from that found in B38 $(6,8$, and 9 mutations are present in orf1, ORFA, and ORFB of HPAG1, respectively). This consistency in the five copies of ISHp609 in B38 indicated that it has been acquired very recently, and that it is probably an active element that is capable of transposition, a property never experimentally demonstrated for a transposable element in $H$. pylori.

Another property associated with the B38 genome relates to the complete absence of four of the 45 genes encoding outer membrane proteins (OMPs) from the four conserved OMP families (Hop, Hor, Hof et Hom) (Additional file 3). B38 lacks $b a b \mathrm{~B}, b a b \mathrm{C}, s a b \mathrm{~B}$, and hom $\mathrm{B}$, four OMPs known to play a major role in adhesion to gastric epithelial cells and possibly in long-term persistence of strains in the human gastric mucosa when associated with peptic ulcer diseases or gastric metaplasia [32]. B38 lacks a high number of adhesin genes among the sequenced genomes.

\section{Comparative genomics and genome evolution}

We then analyzed the genomic rearrangements through pair-wise genomic synteny comparisons between B38 and the eight published Helicobacteriaceae genomes. For five of the isolates (namely, 26695, J99, G27, P12, HPAG1), we confirmed the previously reported relative colinearity of the H.pylori genomes. This colinearity is mainly interrupted by insertion elements, the cagPAI, and genes encoding hypothetical proteins [33]. However, unexpectedly, conserved synteny highlighted an almost complete colinearity never described so far, between B38 and Shi470 (Figure 4). Shi470 is a clinical isolate from the gastric antrum of an Amerindian resident of a remote Amazonian village in Peru, and was thought to be related to strains from East Asia [RefSeq:NC_010698]. This unexpected absence of major genomic rearrangements between the two genomes prompted us to compare the genome of these two isolates more closely, as a way of better understanding $H$. pylori genome evolution. B38 lacks 174 Shi470 genes, of which 70 genes cluster in three insertion blocks: one corresponds to the well character- 


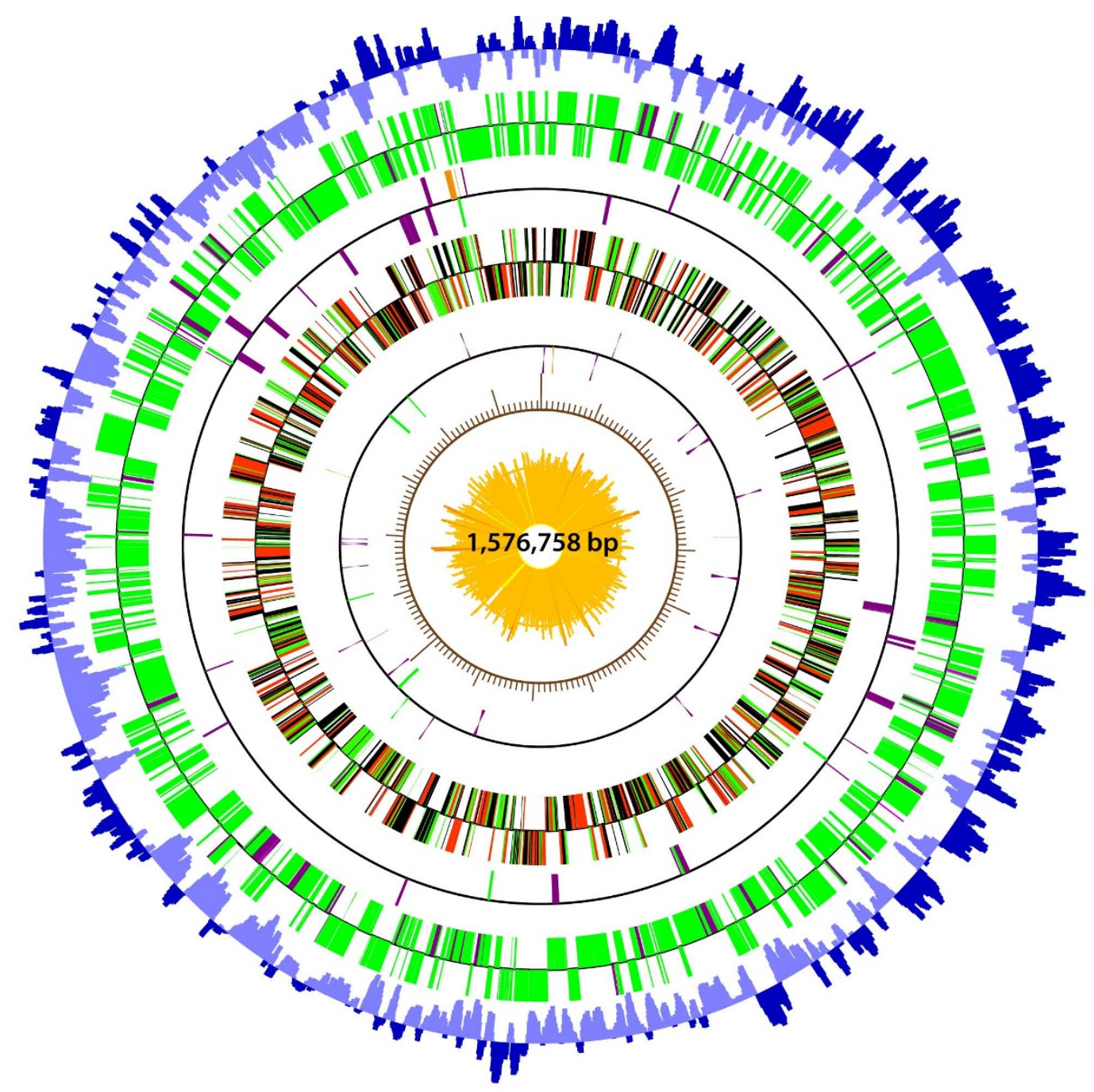

From outside:

- GC skew (window 2500, step 500)

- Total CDSs (green) with pseudogenes/partial genes (purple)

- CDSs coding for hypothetical restriction/modification systems, phages proteins or Insertion Sequences ISHp609

- Total CDSs according to the matrix defined for gene identification (matrix $n^{\circ} 1$ in red, matrix $n^{\circ} 2$ in black, matrix $n^{\circ} 3$ in green) - RNA (rRNA in green, tRNA in purple and misc_RNA

- Rule

- GC \% (window 5000, step 2000)

Figure 3 Genome map of Helicobacter pylori strain B38. From outside to inside: -GC skew (window 2500, step 500) in blue. -Total CDSs (green) with pseudogenes/partial genes (purple). -CDSs coding for hypothetical restriction/modification systems (purple), phage proteins (orange), or insertion sequences (ISHp609) (green). -Total CDSs according to the matrix defined for gene identification (matrix $n^{\circ} 1$ in red, matrix $\mathrm{N}^{\circ} 2$ in black, matrix $n^{\circ} 3$ in green). -RNA (rRNA in green, tRNA in purple and misc_RNA in red). -Rule. -GC\% (window 5000, step 2000) in yellow. Red arrow indicates the position of the origin of replication.

ized cagPAI; another to a block of 33 CDSs, mainly remnants from a conjugative plasmid (presence of TraG, VirB11, toposiomerase I, ComB3, homologs of conjugal plasmid transfer system); and the third corresponds to a block that includes 7 CDSs encoding hypothetical proteins, as well as one CDS encoding an exodeoxyribonuclease subunit which is unique to the Shi 470 isolate.
Conversely, loss of synteny was also due to the presence of 110 CDSs in B38 that were not present in Shi470. Forty-three of these CDSs appeared as clusters within eight loci. Twenty corresponded to ISHp609 (5 complete and conserved copies of ISHp 609 each comprising orf1, orf2, ORFA and ORFB) [31], which interrupts HELPY0571, HELPY0700 (both encoding restriction/ 


\begin{tabular}{|c|c|c|c|c|c|c|c|c|c|c|c|c|c|c|c|c|c|c|c|}
\hline \multirow{2}{*}{$\begin{array}{l}\text { Species and strains } \\
\text { CELLULAR PROCESSES AND SIGNALING }\end{array}$} & \multicolumn{3}{|c|}{ H. p B38 } & \multicolumn{2}{|c|}{ H.p 26695} & \multicolumn{2}{|c|}{ H.p J99 } & \multicolumn{2}{|c|}{ H.p HPAG1 } & \multicolumn{2}{|c|}{ H.p Shi470 } & \multicolumn{2}{|c|}{ H.p G27 } & \multicolumn{2}{|c|}{ H.p P12 } & \multicolumn{2}{|c|}{ H. acinonychis } & \multicolumn{2}{|c|}{ H. hepaticus } \\
\hline & & & & & & & & & & & & & & & & & & & \\
\hline $\begin{array}{l}\text { Cell cycle control, cell division, chromosome } \\
\text { partitioning }\end{array}$ & $\mathrm{D}$ & 39 & $2.55 \%$ & 39 & $2.38 \%$ & 38 & $2.46 \%$ & 34 & $2.21 \%$ & 38 & $2.39 \%$ & 37 & $2.30 \%$ & 39 & $2.38 \%$ & 37 & $2.10 \%$ & 33 & $1.78 \%$ \\
\hline Cell wall/membrane/envelope biogenesis & M & 109 & $7.13 \%$ & 106 & $6.48 \%$ & 105 & $6.81 \%$ & 105 & $6.82 \%$ & 104 & $6,53 \%$ & 108 & $6.70 \%$ & 106 & $6.47 \%$ & 109 & $6.20 \%$ & 134 & $7.24 \%$ \\
\hline Cell motility & $\mathrm{N}$ & 65 & $4.26 \%$ & 58 & $3.54 \%$ & 60 & $3.89 \%$ & 57 & $3.70 \%$ & 55 & $3.46 \%$ & 59 & $3.66 \%$ & 61 & $3.72 \%$ & 57 & $3.24 \%$ & 68 & $3.68 \%$ \\
\hline $\begin{array}{l}\text { Posttranslational modification, protein } \\
\text { turnover, chaperones }\end{array}$ & $\mathrm{O}$ & 71 & $4.65 \%$ & 74 & $4.52 \%$ & 75 & $4.86 \%$ & 74 & $4.81 \%$ & 77 & $4.84 \%$ & 76 & $4.72 \%$ & 76 & $4.64 \%$ & 73 & $4.15 \%$ & 85 & $4.60 \%$ \\
\hline Signal transduction mechanisms & $\mathrm{T}$ & 54 & $3.53 \%$ & 52 & $3.18 \%$ & 56 & $3.63 \%$ & 47 & $3.05 \%$ & 46 & $2.89 \%$ & 51 & $3.17 \%$ & 57 & $3.48 \%$ & 46 & $2.62 \%$ & 68 & $3.68 \%$ \\
\hline $\begin{array}{l}\text { Intracellular trafficking, secretion, vesicular } \\
\text { transport }\end{array}$ & U & 59 & $3.86 \%$ & 76 & $4.64 \%$ & 73 & $4.73 \%$ & 66 & $4.29 \%$ & 71 & $4.46 \%$ & 74 & $4.59 \%$ & 83 & $5.06 \%$ & 56 & $3.18 \%$ & 60 & $3.24 \%$ \\
\hline Defense mechanisms & $\mathbf{v}$ & 57 & $3.73 \%$ & 52 & $3.18 \%$ & 54 & $3.50 \%$ & 53 & $3.44 \%$ & 51 & $3.20 \%$ & 53 & $3.29 \%$ & 52 & $3.17 \%$ & 42 & $2.39 \%$ & 38 & $2.05 \%$ \\
\hline Extracellular structures & w & 0 & $0.00 \%$ & 0 & $0.00 \%$ & 0 & $0.00 \%$ & 1 & $0.07 \%$ & 1 & $0.06 \%$ & 1 & $0.06 \%$ & 0 & 0 & 0 & $0 \%$ & 1 & $0.05 \%$ \\
\hline Cytoskeleton & Z & 0 & $0.00 \%$ & 0 & $0.00 \%$ & 0 & $0.00 \%$ & 0 & $0.00 \%$ & 0 & $0.00 \%$ & 0 & 0 & 0 & 0 & 0 & $0 \%$ & 1 & $0.05 \%$ \\
\hline \multicolumn{20}{|l|}{ INFORMATION STORAGE AND PROCESSING } \\
\hline Chromatin structure and dynamics & B & 1 & $0.07 \%$ & 1 & $0.06 \%$ & 0 & 0 & 1 & $0.07 \%$ & 1 & $0.06 \%$ & 1 & $0.06 \%$ & 1 & $0.06 \%$ & 0 & $0 \%$ & 1 & $0.05 \%$ \\
\hline Translation, ribosomal structure, biogenesis & J & 134 & $8.77 \%$ & 138 & $8.43 \%$ & 141 & $9.14 \%$ & 137 & $8.90 \%$ & 138 & $8.67 \%$ & 136 & $8.44 \%$ & 139 & $8.48 \%$ & 134 & $7.62 \%$ & 148 & $8.00 \%$ \\
\hline Transcription & $\mathrm{K}$ & 53 & $3.47 \%$ & 44 & $2.69 \%$ & 46 & $2.98 \%$ & 48 & $3.12 \%$ & 43 & $2.70 \%$ & 49 & $3.04 \%$ & 49 & $2.99 \%$ & 43 & $2.45 \%$ & 59 & $3.19 \%$ \\
\hline Replication, recombination and repair & $\mathbf{L}$ & 154 & $10.08 \%$ & 177 & $10.69 \%$ & 155 & $10.05 \%$ & 149 & $9.68 \%$ & 150 & $9.42 \%$ & 171 & $10.62 \%$ & 163 & $9.95 \%$ & 155 & $8.82 \%$ & 100 & $5.41 \%$ \\
\hline \multicolumn{20}{|l|}{ METABOLISM } \\
\hline Energy prodcution and conversion & C & 90 & $5.89 \%$ & 89 & $5.44 \%$ & 87 & $5.64 \%$ & 93 & $6.04 \%$ & 93 & $5.84 \%$ & 92 & $5.71 \%$ & 93 & $5.67 \%$ & 87 & $4.95 \%$ & 118 & $6.38 \%$ \\
\hline Amino acid transport & $\mathrm{E}$ & 151 & $9.88 \%$ & 145 & $8.86 \%$ & 152 & $9.85 \%$ & 146 & $9.49 \%$ & 153 & $9.61 \%$ & 150 & $9.31 \%$ & 150 & $9.15 \%$ & 160 & $9.10 \%$ & 200 & $10.81 \%$ \\
\hline Nucleotide transport & $\mathrm{F}$ & 46 & $3.01 \%$ & 45 & $2.75 \%$ & 47 & $3.05 \%$ & 45 & $2.92 \%$ & 44 & $2.76 \%$ & 47 & $2.92 \%$ & 47 & $2.87 \%$ & 47 & $2.67 \%$ & 58 & $3.14 \%$ \\
\hline Carbohydrate transport & G & 60 & $3.93 \%$ & 56 & $3.42 \%$ & 57 & $3.69 \%$ & 55 & $3.57 \%$ & 63 & $3.96 \%$ & 55 & $3.41 \%$ & 59 & $3.60 \%$ & 59 & $3.35 \%$ & 76 & $4.11 \%$ \\
\hline Coenzyme transport & $\mathrm{H}$ & 75 & $4.91 \%$ & 73 & $4.46 \%$ & 75 & $4.86 \%$ & 75 & $4.87 \%$ & 75 & $4.71 \%$ & 75 & $4.66 \%$ & 76 & $4.64 \%$ & 67 & $3.81 \%$ & 87 & $4.70 \%$ \\
\hline Lipid transport & 1 & 50 & $3.27 \%$ & 49 & $2.99 \%$ & 49 & $3.18 \%$ & 50 & $3.25 \%$ & 47 & $2.95 \%$ & 51 & $3.17 \%$ & 51 & $3.11 \%$ & 47 & $2.67 \%$ & 54 & $2.92 \%$ \\
\hline Inorganic ion transport & $P$ & 97 & $6.35 \%$ & 94 & $5.74 \%$ & 100 & $6.48 \%$ & 94 & $6.11 \%$ & 103 & $6.47 \%$ & 97 & $6.02 \%$ & 98 & $5.98 \%$ & 95 & $5.40 \%$ & 125 & $6.76 \%$ \\
\hline $\begin{array}{l}\text { Secondary matabolites biosynthesis, } \\
\text { transport }\end{array}$ & Q & 26 & $1.70 \%$ & 25 & $1.53 \%$ & 25 & $1.62 \%$ & 23 & $1.50 \%$ & 23 & $1.45 \%$ & 22 & $1.37 \%$ & 26 & $1.59 \%$ & 24 & $1.36 \%$ & 37 & $2.00 \%$ \\
\hline \multicolumn{20}{|l|}{ POORLY CHARACTERIZED } \\
\hline General function prediction only & $\mathrm{R}$ & 174 & $11.39 \%$ & 173 & $10.57 \%$ & 178 & $11.54 \%$ & 160 & $10.40 \%$ & 174 & $10.93 \%$ & 168 & $10.43 \%$ & 175 & $10.68 \%$ & 166 & $9.44 \%$ & 234 & $12.65 \%$ \\
\hline Function unknown & $\mathrm{S}$ & 84 & $5.50 \%$ & 80 & $4.89 \%$ & 71 & $4.60 \%$ & 78 & $5.07 \%$ & 70 & $4.40 \%$ & 84 & $5.21 \%$ & 81 & $4.94 \%$ & 70 & $3.98 \%$ & 113 & $6.11 \%$ \\
\hline $\begin{array}{l}\text { CDS Not Classified to any COG } \\
\text { (Number/\%) }\end{array}$ & & \multicolumn{2}{|c|}{$339 / 22.2$} & \multicolumn{2}{|c|}{$435 / 26.6$} & \multicolumn{2}{|c|}{$363 / 23.5$} & \multicolumn{2}{|c|}{$367 / 23.9$} & \multicolumn{2}{|c|}{$422 / 26.5$} & \multicolumn{2}{|c|}{$395 / 24.5$} & \multicolumn{2}{|c|}{$440 / 26.9$} & \multicolumn{2}{|c|}{$536 / 31.6$} & \multicolumn{2}{|c|}{$479 / 25.9$} \\
\hline TOTAL CDS* & & \multicolumn{2}{|c|}{1528} & \multicolumn{2}{|c|}{1637} & & 1543 & & 1539 & & 1592 & & 1611 & & 1639 & & 696 & & 850 \\
\hline$\%$ CDS at least in one COG & & & $7.81 \%$ & & $3.43 \%$ & & $6.47 \%$ & & $6.15 \%$ & & $3.49 \%$ & & $5.48 \%$ & & $3.15 \%$ & & $.40 \%$ & & $.11 \%$ \\
\hline
\end{tabular}




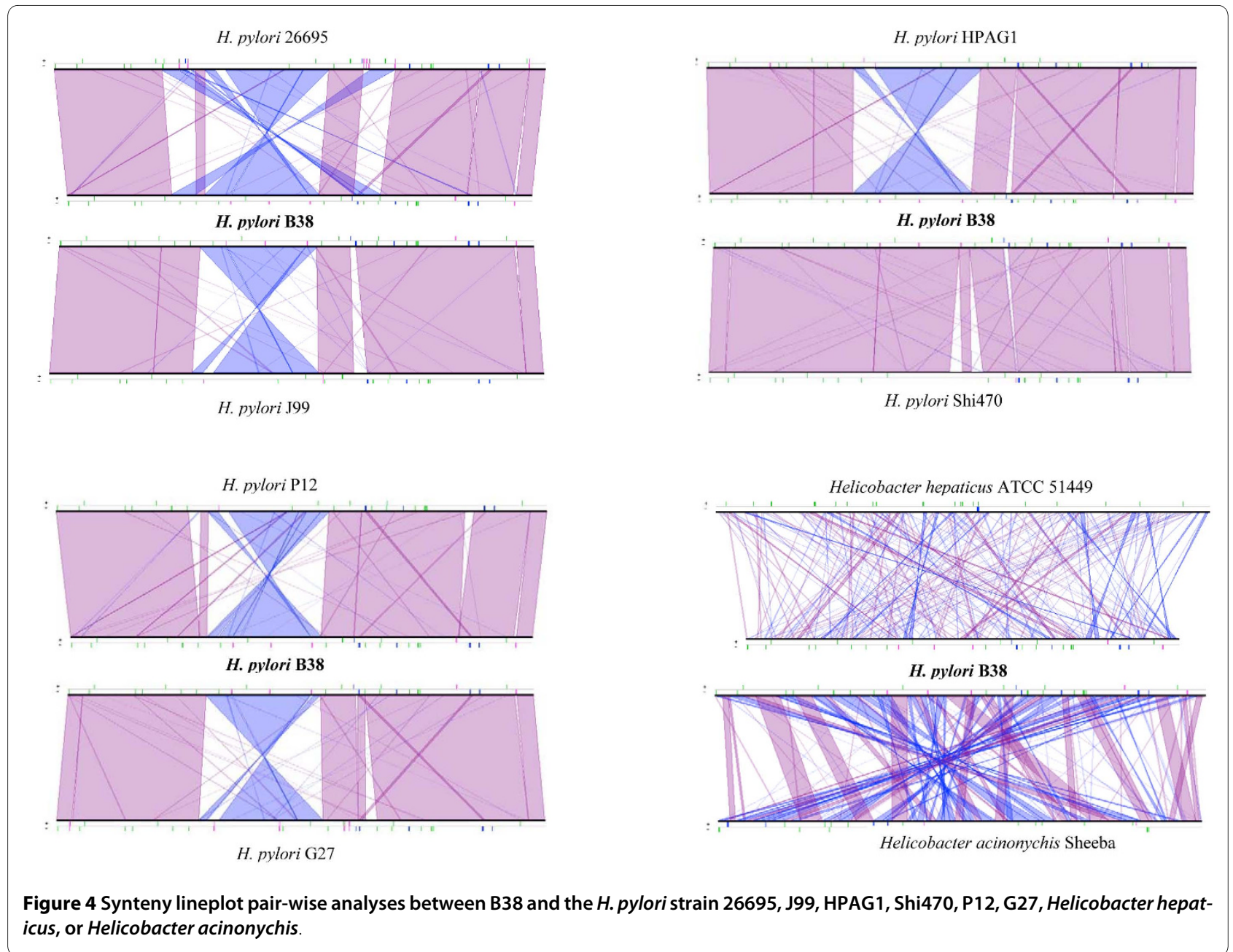

modification systems), HELPY0838 (encoding a putative Rad50 ATPase), HELPY1330 (encoding a putative glycosyl-transferase), and HELPY1529 (a HAC prophage II protein homolog). In addition to these five ISHp609 insertions, loss of synteny was also due to the presence of CDSs in four other loci: i) a cluster of seven genes (HELPY1520 to HELPY1525 and HEPLY1527, HELPY1528 to HELPY1533) encoding HacII prophagelike proteins similar to those found in $H$. acinonychis strain Sheeba [34]; however, the size of the prophage is much larger (32 CDS) in this species, suggesting that the prophage in B38 has been deleted, possibly following the insertion of one copy of ISHp609; ii) a cluster of six genes encoding hypothetical proteins of unknown function (HELPY0051 to HELPY0056); iii) a cluster of three CDSs that are absent in Shi470, HPAG1, J99, P12, and G127, but present in strain 26695, of which two encode alginate-O-acetylation proteins (HELPY0497-498); iv) a cluster of seven CDSs that encode a putative helicase (HELPY0989) and a putative serine kinase (HELPY0990), two functional proteins not found in all of the other sequenced strains.

\section{H. pylori core genome and strain-specific genes}

BLAST score ratio analyses and comparisons between the B38 strain and the six other sequenced genomes, which were analyzed and revised through the MaGe system (Table 1), allowed us to establish that the core of the H. pylori genome consists of 1,275 CDSs. This number is slightly higher than that recently published by McClain and colleagues who identified 1,237 genes, as it takes into account additional CDSs detected by the MaGe system [35]. This number is lower than that calculated from data presented in Additional file 1 (1,358 genes) based on the macroarray hybridization analysis of 120 isolates. This approach overestimated the number of ubiquitous CDSs, as all small CDS ( $<350 \mathrm{bp}$ ) from the 26695 strain genome were excluded from the analysis, and thus were systematically counted as ubiquitous CDSs.

To identify strain-specific genes present in the B38 strain but absent from the other sequenced strains, we studied the putative orthologous relationship between two genomes i.e. gene couples who satisfy Bi-directional Best Hit $(\mathrm{BBH})$ criteria. Criteria included a minimum of $30 \%$ sequence identity and $80 \%$ of the length of the small- 
est protein (Additional file 4). Only 16 CDSs were found to be unique to the B38 strain: nine seemed to be complete and thus putatively functional; six were shown to encode the putative HacII prophage-like proteins (HELPY1521-1522-1523-1524-1525-1527); three were found to encode hypothetical proteins (HELPY0409, HELPY0645 and HELPY0996), and seven corresponded to fragments of genes (partial genes) coding for either conserved hypothetical proteins, prophage-like sequences or for a restriction enzyme. Using the same methodology, we looked for genes that were present in the various $H$. pylori strains and absent in B38 (Additional file 5). If compared pair-wise, the number of CDSs absent in B38 was between 105 and 175. The only genes that were found to be exclusively absent in B38 corresponded to those of the cagPAI (Additional file 5), the well-known cluster of genes involved in the induction of a strong inflammatory response.

\section{Specific properties associated with the genomes of strains belonging to the MALT lymphoma PAI minus cluster}

Of the 19 strains belonging to the MALT lymphoma PAI minus cluster, all 19 contained the vacAm2 allele; 16 exhibited an $\mathrm{s} 2 \mathrm{~m} 2$ genotype, indicating that they encode a non-functional cytotoxin, and three exhibited an $\mathrm{s} 1 \mathrm{~m} 2$ genotype [18]. We then investigated whether the properties found to be unique to strain B38 are shared by the strains belonging to the cluster of the MALT lymphoma PAI-minus cluster. The search for the presence of the HacII-like prophage was done through hybridization using internal fragments of HELPY1521, HELPY1525, and HELPY1526 as probes. Four of the 19 strains (21\%, including B38) of the MALT lymphoma PAI minus cluster, contained HacII prophage-like sequences. By contrast, 1/24 (4\%) strains isolated from patients with MALT lymphoma containing cagPAI, 2/33 (6\%) strains from patients suffering from gastritis and $2 / 27$ strains $(7.4 \%)$ from those with duodenal ulcers contained HacII prophage-like sequences. Furthermore, the presence of the two adjacent HELPY0989 and HELPY0990 genes encoding a helicase and a serine kinase, respectively, not previously found in the other sequenced genomes as functional proteins were found in three of the 19 strains $(16 \%)$ of the B38 cluster. These two genes were not detected in the other MALT lymphoma strains (cagPAI positive), nor within the 22 isolates associated with gastritis and peptic ulcers. Finally, three clustered conservative mutations in $g \operatorname{lmM}$ (HELPYO072 - $\mathrm{Ala}_{332}, \mathrm{Leu}_{333}$ ), leading to the absence of amplification of the 294-bp internal fragment of the phosphoglucosamine mutaseencoding gene [36], were observed in five of the 19 MALT lymphoma PAI minus isolates (26\%). However, these mutations were not found in any of the 120 clinical isolates of this study, nor were they found in more than
$400 \mathrm{H}$. pylori isolates associated with gastritis, peptic ulcers or metaplasia that were tested with identical oligonucleotides (personal data). These conservative mutations may be indicative of a selective pressure to maintain these mutations, together with a property encoded by a gene present in close proximity to $\operatorname{glm} M$, a property that has yet to be identified. Thus, although none of the unique properties of B38 were shared by all MALT strains of the cluster, characterizing a cagPAI minus isolate containing either $\operatorname{glm} M$ mutations or HELPY0989-0990 genes may be predictive of MALT lymphoma, as these two characteristics were found exclusively among the strains of this cluster.

\section{Conclusion}

The study was initiated with the aim of gaining insight into the existence of bacterial determinism for gastric extra-nodal marginal zone B-cell MALT lymphoma. DNA hydridization against the whole genome of 120 clinical isolates revealed a cluster of $19 \mathrm{H}$. pylori strains, all completely deprived of cagPAI sequences originating from patients with MALT lymphoma. We sequenced the genome of strain B38, a representative of this cluster, and describe the first genome sequence of a cagPAI minus $H$. pylori strain. The absence of the cagPAI, including that of several non-ubiquitous genes, makes the $\mathrm{B} 38$ genome the smallest $H$. pylori genome described to date. The cagPAI minus B38 strain lacks a functional cytotoxin (vacAs2m2) as well as genes encoding the major adhesion factors (absence of $b a b \mathrm{~B}, b a b \mathrm{C}, s a b \mathrm{~B}$, and homB); thus, compared with well-known pro-inflammatory $H$. pylori isolates, it appears to be deprived of all known pathogenic determinants, but is nonetheless associated with gastric neoplasia. Further investigation is required to fully understand the difference in fitness between these strains with low pro-inflammatory profiles and the human host factors that may play a significant role in the development of gastric MALT lymphoma.

\section{Methods}

\section{H. pylori strains, and growth}

We examined $120 \mathrm{H}$. pylori strains isolated from patients from different areas of France enrolled in 3 multi-center studies carried out by 1) the Groupe d'Etude Français des Helicobacter (G.E.F.H.), 2) the Groupe d'Etude Français des Lymphomes Digestifs (G.E.L.D.) [37] and of the Fédération Française de Cancérologie Digestive (F.F.C.D.) [38], and 3) the Groupe d'Etude des Lymphomes de l'Adulte (G.E.L.A.). Criteria for patient inclusion were age ( $>55$ years), suffering from chronic gastritis $(n=33)$, duodenal ulcer without intestinal metaplasia (27), intestinal metaplasia without ulcer $(\mathrm{n}=17)$. We identified 43 strains from patients with gastric MALT lymphoma. $H$. pylori was isolated from one biopsy specimen following 
biopsy homogenization and culture under microaerophilic conditions $\left(5-6 \% \mathrm{O}_{2}, 8-10 \% \mathrm{CO}_{2}, 80-85 \% \mathrm{~N}_{2}\right)$ on blood agar medium (BA; Oxoid blood agar base $\mathrm{N}^{\circ} 2$ ) supplemented with $10 \%$ horse blood, as reported previously [39]. One colony was selected at random from each primary culture; it was then sub-cultured and used to prepare chromosomal DNA. This DNA was extracted from 48-hour-old confluent cells using the QIAamp Tissue kit (Qiagen, Chatsworth, CA) according to the manufacturer's recommendations.

\section{In house DNA macroarray membrane preparation}

A total of 254 PCR products were amplified in four 96well microtiter plates, corresponding to 41 ubiquitous and 213 non-ubiquitous genes from the genome of strain 26695 as previously described [39]. Briefly, amplification reactions were performed in $2 \times 100 \mu \mathrm{l}$ reaction volumes, in which $2 \mu \mathrm{l}$ of DNA corresponding to the recombinant plasmid containing the full-length CDS (CoDing Sequence) inserted into the pILL570-derivative vector was used as template. Each PCR product was sequenced to confirm the identity of the gene, and was then spotted in triplicate onto a nylon membrane (Qfilter, Genetix 22.2 $\times 22.2 \mathrm{~cm}, \mathrm{~N}+$ ) using a Qpix robot (Genetix). Denaturated 26695 genomic DNA was spotted in triplicate at the four corners of the membrane (positive controls) and seven squares were left empty as negative controls. Following spot deposition, membranes were fixed for 15 minutes in $0.5 \mathrm{M} \mathrm{NaOH} 1.5 \mathrm{M} \mathrm{NaCl}$, washed briefly in distilled water, and stored wet at $-20^{\circ} \mathrm{C}$ until use [39].

Aliquots of $250 \mu \mathrm{l}$ of DNA were labeled by random priming with $2 \mu \mathrm{l}$ of ${ }^{33} \mathrm{P}-\mathrm{dCTP}$. Labeling was performed for 3 hours at room temperature. Unincorporated radionucleotides were removed by purification on Quick Spin Sephadex G-25 columns (Roche Diagnostics). Immediately before being used for hybridization experiments, the sonicated, labeled, and purified chromosomal DNA was heat-denaturated and cooled on ice. Hybridization was conducted in $5 \mathrm{ml}$ prewarmed $\left(65^{\circ} \mathrm{C}\right)$ hybridization mixtures containing the heat denaturated probe, with overnight incubation. Membranes were then washed and exposed for 25 hours to a phosphoimager screen (Molecular Dynamics).

Screens were scanned on a Storm 860 machine (Molecular Dynamics). Image analysis and quantification of hybridization intensities for each spot were performed using the Xdots Reader program (COSE) and determined in pixels [39]. The intensity of the background surrounding each spot was substracted from that of each of the spots. Twenty-one homologous hybridizations were performed. The average intensity of the 41 ubiquitous genes was calculated for each reference array. This number served to allocate a reference array to each heterologous hybridization (average of the ubiquitous spots from the heterologous and the homologous reference hybridizations were not significantly different, Student's test), to calculate the ratio used for normalization. Following normalization, the data were analyzed by attributing a binary score (presence/absence - Additional file 1) or by multidimensional analysis based on continuous intensity values (Figure 1 and Figure 2). To define the cutoff ratio for the presence/absence of a gene, we analyzed the results for the sequenced $H$. pylori 599 DNA hybridized with $H$. pylori 26695; the threshold for the presence of a gene was defined as $>0.25$. The multidimensional analyses (Genesis software) for the hierarchical clustering as well as for the Principal Component Analysis were performed using the 254 continuous values from the 120 heterologous hybridization experiments, each corresponding to $\left(\log _{10}\right.$ normalized intensity values of strain 26695$)$ minus $\left(\log _{10}\right.$ normalized intensity values of the heterologous strain) (i.e. $\log _{26695}-\log _{\text {heterol.strain }}$ ).

\section{Sequencing and annotation of the B38 genome}

Genomic DNA was randomly sheared by nebulization (HydroShear, GeneMachines) and the ends were enzymatically repaired. SmaI fragments $(1.5-4 \mathrm{~kb})$ were inserted into plasmid vector pBAM3/SmaI (derived from pBluescript KS and constructed by R. Heilig). Large (35$45 \mathrm{~kb})$ DNA fragments generated from partial BamHIrestriction were inserted into the cosmid vector $\mathrm{pHC79/}$ BamHI.

Plasmid DNA was prepared with the TempliPhi DNA sequencing template amplification kit (GE HealthcareBio-Sciences). Cosmid DNA was purified with the Montage BAC Miniprep96 Kit (Millipore). Sequencing reactions were performed from both ends of DNA templates using ABI PRISM BigDye Terminator cycle sequencing ready reactions kits and were run on a 3700 or a $3730 \mathrm{xl}$ Genetic Analyzer (Applied Biosystems).

Sequence data base calling was carried out using Phred [40]. Sequences not meeting our production quality criteria (at least 100 bases called with a quality over 20) were discarded. Sequences were screened against plasmid vector and $E$. coli sequences. The traces were assembled using Phrap and Consed [41]. Whole genome shotgun sequencing was performed to ensure approximately 11fold coverage. Autofinish [42] was used to design primers for improving regions of low quality sequence and for primer walking along templates spanning the gaps between contigs. Several strategies were used to orientate contigs and to enable directed PCR-based approaches to span the gaps between contigs. These strategies included linking isolates and a Blast-based approach, which identified contigs with hits to the H. pylori strain 26695 genome. Various combined PCR techniques were used to amplify genomic or cosmid DNA, to close the gaps between the final contigs. Outward-directed primers 
were designed for each of the contig ends; the primer sequences were subsequently checked and confirmed to be unique to the genome. This combined PCR process required approximately 200 PCR reactions pairing each of the primers. In addition, two cosmid isolates containing a rDNA operon copy each, were completely sequenced by sub-cloning into a pSMART-LC vector (Lucigen Corp.). The error rate was less than 1 error per $10,000 \mathrm{bp}$ in the final assembly. The complete genome sequence was obtained from 40153 sequences, resulting in 14-fold coverage.

AMIGene software was used to predict which CDSs were likely to encode proteins [43]. The set of predicted genes underwent automatic functional annotation using the set of tools listed in Vallenet et al. [28]. All these data (syntactic and functional annotations, results of comparative analysis) are stored in a relational database, called PyloriScope. Manual validation of the automatic annotation was performed using the MaGe (Magnifying Genomes, http://www.genoscope.cns.fr) web-based interface, which allows graphic visualization of the annotations enhanced by the synchronized representation of synteny groups in other genomes chosen for comparison.

\section{Accession Numbers}

The EMBL Nucleotide Sequence Database http:// www.ebi.ac.uk/embl accession number for the H. pylori strain B38 chromosome is [EMBL:FM991728].

All data and comparative genomics concerning the $H$. pylori B38 genome are stored in PyloriScope http:// www.genoscope.cns.fr/agc/mage, a related database that is available to the public.

\section{Additional material}

Additional file $\mathbf{1}$ List of the $\mathbf{2 5 4}$ genes of Helicobacter pylori strain 26695 used for gene amplification and preparation of the homemade macroarray membranes. Distribution of each gene in the 120 French isolates of this study associated with gastritis (G), duodenal ulcer (DU), gastric MALT lymphoma (MALT) or metaplasia (META). The percentages were based on the binary analysis (presence/absence/) according to the normalization process and the cutoff ratio described in Material ad Methods. "HPXXXX+", genes were designated as ubiquitous genes based on previous comparative analysis [25]; "HPXXXX" are the non-ubiquitous genes; the 48 most discriminatory genes identified as key combinations of variables (genes/axes) from the Principal Component Analysis, which were used for the clustering analysis, are in bold (Figure 2).

Additional file $\mathbf{2}$ CDSs of $\mathrm{B} 38$ strain involved in restriction/modification systems classified according to the gene status.

Additional file 3 Distribution of the outer membrane proteins (OMPs) encoding genes in the 7 Helicobacter pylori genome sequences. (B38, J99, 26695, HPAG1, Shi470, G27, P12). The genes are classified according to the hop, hor, hof, and hom gene families. The numbers refer to the name of the CDS in each genome (for example: 0009 in 26695 refers to HP0009, 0007 in B38 refers to HELPY0007). "x" indicates a complete absence of the gene. Two or three names separated by a "/" reveals the presence of a pseudogene.
Additional file 4 Number of CDSs in the B38 strain that are absent in the J99, 26695, HPAG1 or Shi470 Helicobacter pylori strains classified by protein functions.

Additional file $\mathbf{5}$ Number of CDSs (listed by protein functions) of the Helicobacter pylori J99, 26695, HPAG1 and Shi470, G27 and P12 strains that are absent in strain B38 respectively. * All strains: J99, 26695, HPAG1, Shi470, G27, and P12. ** The number depends on the strain chosen for reference.

\section{Authors' contributions}

JMT carried out the macroarrays, the molecular genetic studies, and participated to the genome assembly. CB-E carried out the major part of the manual annotation of the genome together with $\mathrm{PL}, \mathrm{HDR}$, and IB. CB and LM carried out to the genome sequencing and assembly. CM, ZR and $\mathrm{AL}$ were involved in the automatic annotation, comparative genomics, and administration of the MaGe system. JYC, MAD and SC participated to the home made DNA arrays preparation, and the statistical analyses. CB, AR-F, AC-M, DL, FM and JCD collected the clinical isolates. AL designed the study, analysed the results, and drafted the manuscript. JR analysed the results, and drafted the manuscript. All authors read and approved the final manuscript.

\section{Acknowledgements}

Array-based comparative genomic hybridization of $H$. pylori isolates was supported by funds provided by IRMAD (Institut de Recherche des Maladies de I'Appareil Digestif), Genopole, and Institut Pasteur. Sequencing of the B38 genome, as well as the manual annotation and curation, was supported by funds from Genopole, Institut Pasteur and the INCA Consortium/European FP6 program (LSHC-CT-2005-018704). This study was also supported by a grant from Agence Nationale de la Recherche (ANR) under the scope of the PFTV MicroScope project. Ivo Gomperts Boneca is funded by an ERC starting grant (202283-PGNfromSHAPEtoVIR). The authors thank the members of Groupe d'Etude Français des Helicobacter (G.E.F.H).

\section{Author Details}

1Institut Pasteur, Génotypage des Pathogènes et Santé Publique, Paris, France, 2 Institut Pasteur, PF4 Analyse et Intégration Génomiques, Paris, France, 3 Université Victor Segalen, INSERM U853, Bordeaux, France, ${ }^{4}$ Institut Pasteur PF2 Puces à ADN, Paris, France, Institut Pasteur, PF1 Génomique, Paris, France, ${ }^{6} \mathrm{CEA}$, Direction des Sciences du Vivant, Institut de Génomique, Genoscope \& CNRS-UMR 8030, Laboratoire d'Analyse Bioinformatique en Génomique et Métabolisme, Evry, France, ${ }^{7} \mathrm{CHU}$ de Poitiers, EA4331, LITEC, Bactériologie, Poitiers, France, ${ }^{8 H}$ Ho pital Saint Antoine, Paris, France, ${ }^{9 H o ̂ p i t a l ~ V i l l e n e u v e ~ S a i n t ~}$ Georges, France, ${ }^{10}$ nstitut Pasteur, Unité postulante de Pathogenèse de Helicobacter, Paris, France, ${ }^{11}$ Institut Pasteur, Groupe Biologie et génétique de la paroi bactérienne, Paris, France, ${ }^{12 I N S E R M, ~ G r o u p e ~ A v e n i r, ~ P a r i s, ~ F r a n c e, ~}$

${ }^{13}$ Hôpital Hôtel Dieu, Paris, France, ${ }^{14}$ Hôpital Henri Mondor, Créteil, France and

15Université Paris Descartes, Faculté de Médecine, Hôpital Cochin, Paris, France

Received: 26 February 2010 Accepted: 10 June 2010

Published: 10 June 2010

\section{References}

1. Blaser MJ, Atherton JC: Helicobacter pylori persistence: biology and disease. J Clin Invest 2004, 113:321-333.

2. Forman D, Newell DG, Fullerton F, Yarnell JW, Stacey AR, Wald N, Sitas F: Association between infection with Helicobacter pylori and risk of gastric cancer: evidence from a prospective investigation. BMJ 1991, 302:1302-1305.

3. Isaacson P, Wright DH, Jones DB: Malignant lymphoma of true histiocytic (monocyte/macrophage) origin. Cancer 1983, 51:80-91.

4. Uemura N, Okamoto S, Yamamoto S, Matsumura N, Yamaguchi S, Yamakido M, Taniyama K, Sasaki N, Schlemper RJ: Helicobacter pylori infection and the development of gastric cancer. N Eng/ J Med 2001, 345:784-789.

5. Gerhard M, Rad R, Prinz C, Naumann M: Pathogenesis of Helicobacter pylori infection. Helicobacter 2002, 7(Suppl 1):17-23. 
6. Parsonnet J, Friedman GD, Orentreich N, Vogelman H: Risk for gastric cancer in people with CagA positive or CagA negative Helicobacter pylori infection. Gut 1997, 40:297-301.

7. Leunk RD, Johnson PT, David BC, Kraft WG, Morgan DR: Cytotoxic activity in broth-culture filtrates of Campylobacter pylori. J Med Microbiol 1988, 26:93-99.

8. Cover TL, Blanke SR: Helicobacter pylori VacA, a paradigm for toxin multifunctionality. Nat Rev Microbiol 2005, 3:320-332.

9. Ilver D, Arnqvist A, Ogren J, Frick IM, Kersulyte D, Incecik ET, Berg DE, Covacci A, Engstrand L, Boren T: Helicobacter pylori adhesin binding fucosylated histo-blood group antigens revealed by retagging. Science 1998, 279:373-377.

10. Mahdavi J, Sondén B, Hurtig M, Olfat FO, Forsberg L, Roche N, Angstrom J, Larsson T, Teneberg S, Karlsson KA, Altraja S, Wadström T, Kersulyte D, Berg DE, Dubois A, Petersson C, Magnusson KE, Norberg T, Lindh F, Lundskog BB, Arnqvist A, Hammarström L, Borén T: Helicobacter pylori SabA adhesin in persistent infection and chronic inflammation. Science 2002, 297:573-578.

11. Bai Y, Zhang YL, Wang JD, Lin HJ, Zhang ZS, Zhou DY: Conservative region of the genes encoding four adhesins of Helicobacter pylori: cloning, sequence analysis and biological information analysis. Di $Y_{i}$ Jun Yi Da Xue Xue Bao 2002, 22:869-871.

12. Oleastro M, Cordeiro R, Yamaoka Y, Queiroz D, Megraud F, Monteiro L, Menard A: Disease association with two Helicobacter pylori duplicate outer membrane protein genes, homB and homA. Gut Pathog 2009, 1:12.

13. Walz A, Odenbreit S, Mahdavi J, Boren T, Ruhl S: Identification and characterization of binding properties of Helicobacter pylori by glycoconjugate arrays. Glycobiology 2005, 15:700-708

14. Backstrom A, Lundberg C, Kersulyte D, Berg DE, Boren T, Arnqvist A: Metastability of Helicobacter pylori bab adhesin genes and dynamics in Lewis b antigen binding. Proc Natl Acad Sci USA 2004, 101:16923-16928.

15. Franco AT, Israel DA, Washington MK, Krishna U, Fox JG, Rogers AB, Neish AS, Collier-Hyams L, Perez-Perez GI, Hatakeyama M, Whitehead R, Gaus IC, O'Brien DP, Romero-Gallo J, Peek RM Jr: Activation of beta-catenin by carcinogenic Helicobacter pylori. Proc Natl Acad Sci USA 2005, 102:10646-10651

16. Broutet N, Moran A, Hynes S, Sakarovitch C, Megraud F: Lewis antigen expression and other pathogenic factors in the presence of atrophic chronic gastritis in a European population. J Infect Dis 2002, 185:503-512.

17. Koehler $\mathrm{Cl}$, Mues MB, Dienes HP, Kriegsmann J, Schirmacher P, Odenthal $\mathrm{M}$ : Helicobacter pylori genotyping in gastric adenocarcinoma and MALT lymphoma by multiplex PCR analyses of paraffin wax embedded tissues. Mol Pathol 2003, 56:36-42.

18. Lehours P, Menard A, Dupouy S, Bergey B, Richy F, Zerbib F, RuskoneFourmestraux A, Delchier JC, Megraud F: Evaluation of the association of nine Helicobacter pylori virulence factors with strains involved in lowgrade gastric mucosa-associated lymphoid tissue lymphoma. Infect Immun 2004, 72:880-888.

19. Lehours $P$, Zheng Z, Skoglund A, Megraud F, Engstrand L: Is there a link between the lipopolysaccharide of Helicobacter pylori gastric MALT lymphoma associated strains and lymphoma pathogenesis? PLoS One 2009, 4:e7297.

20. Tomb JF, White O, Kerlavage AR, Clayton RA, Sutton GG, Fleischmann RD, Ketchum KA, Klenk HP, Gill S, Dougherty BA, Nelson K, Quackenbush J, Zhou L, Kirkness EF, Peterson S, Loftus B, Richardson D, Dodson R, Khalak HG, Glodek A, McKenney K, Fitzegerald LM, Lee N, Adams MD, Hickey EK Berg DE, Gocayne JD, Utterback TR, Peterson JD, Kelley JM, et al: The complete genome sequence of the gastric pathogen Helicobacter pylori. Nature 1997, 388:539-547.

21. Oh JD, Kling-Backhed H, Giannakis M, Xu J, Fulton RS, Fulton LA, Cordum HS, Wang C, Elliott G, Edwards J, Mardis ER, Engstrand LG, Gordon Jl: The complete genome sequence of a chronic atrophic gastritis Helicobacter pylori strain: evolution during disease progression. Proc Natl Acad Sci USA 2006, 103:9999-10004.

22. Baltrus DA, Amieva MR, Covacci A, Lowe TM, Merrell DS, Ottemann KM, Stein M, Salama NR, Guillemin K: The complete genome sequence of Helicobacter pylori strain G27. J Bacterio/ 2009, 191:447-448.

23. Salama N, Guillemin K, McDaniel TK, Sherlock G, Tompkins L, Falkow S: A whole-genome microarray reveals genetic diversity among Helicobacter pylori strains. Proc Natl Acad Sci USA 2000, 97:14668-14673.
24. Gressmann H, Linz B, Ghai R, Pleissner KP, Schlapbach R, Yamaoka Y, Kraft C, Suerbaum S, Meyer TF, Achtman M: Gain and loss of multiple genes during the evolution of Helicobacter pylori. PLoS Genet 2005, 1:e43.

25. Raymond J, Thiberge JM, Kalach N, Bergeret M, Dupont C, Labigne A Dauga C: Using macro-arrays to study routes of infection of Helicobacter pylori in three families. PLoS One 2008, 3:e2259.

26. Nilsson C, Sillen A, Eriksson L, Strand ML, Enroth H, Normark S, Falk P, Engstrand L: Correlation between cag pathogenicity island composition and Helicobacter pylori-associated gastroduodenal disease. Infect Immun 2003, 71:6573-6581.

27. Ali M, Khan AA, Tiwari SK, Ahmed N, Rao LV, Habibullah CM: Association between cag-pathogenicity island in Helicobacter pylori isolates from peptic ulcer, gastric carcinoma, and non-ulcer dyspepsia subjects with histological changes. World J Gastroenterol 2005, 11:6815-6822.

28. Vallenet D, Labarre L, Rouy Z, Barbe V, Bocs S, Cruveiller S, Lajus A, Pascal G, Scarpelli C, Medigue C: MaGe: a microbial genome annotation system supported by synteny results. Nucleic Acids Res 2006, 34:53-65

29. Xu Q, Morgan RD, Roberts RJ, Blaser MJ: Identification of type II restriction and modification systems in Helicobacter pylori reveals their substantial diversity among strains. Proc Natl Acad Sci USA 2000, 97:9671-9676

30. Lin LF, Posfai J, Roberts RJ, Kong H: Comparative genomics of the restriction-modification systems in Helicobacter pylori. Proc Natl Acad SciUSA 2001, 98:2740-2745.

31. Kersulyte D, Kalia A, Zhang M, Lee HK, Subramaniam D, Kiuduliene L, Chalkauskas H, Berg DE: Sequence organization and insertion specificity of the novel chimeric ISHp609 transposable element of Helicobacter pylori. J Bacteriol 2004, 186:7521-7528.

32. Colbeck JC, Hansen LM, Fong JM, Solnick JV: Genotypic profile of the outer membrane proteins BabA and BabB in clinical isolates of Helicobacter pylori. Infect Immun 2006, 74:4375-4378.

33. Alm RA, Trust TJ: Analysis of the genetic diversity of Helicobacter pylori: the tale of two genomes. J Mol Med 1999, 77:834-846.

34. Eppinger M, Baar C, Linz B, Raddatz G, Lanz C, Keller H, Morelli G, Gressmann H, Achtman M, Schuster SC: Who ate whom? Adaptive Helicobacter genomic changes that accompanied a host jump from early humans to large felines. PLoS Genet 2006, 2:e120.

35. McClain MS, Shaffer CL, Israel DA, Peek RM Jr, Cover TL: Genome sequence analysis of Helicobacter pylori strains associated with gastric ulceration and gastric cancer. BMC Genomics 2009, 10:3.

36. Kansau I, Raymond J, Bingen E, Courcoux P, Kalach N, Bergeret M, Braimi N, Dupont C, Labigne A: Genotyping of Helicobacter pylori isolates by sequencing of PCR products and comparison with the RAPD technique. Res Microbiol 1996, 147:661-669.

37. Levy M, Copie-Bergman C, Traulle C, Lavergne-Slove A, Brousse N, Flejou $J$ J, de Mascarel A, Hemery F, Gaulard P, Delchier JC: Conservative treatment of primary gastric low-grade B-cell lymphoma of mucosaassociated lymphoid tissue: predictive factors of response and outcome. Am J Gastroenterol 2002, 97:292-297.

38. Lehours P, Dupouy S, Bergey B, Ruskone-Foumestraux A, Delchier JC, Rad R, Richy F, Tankovic J, Zerbib F, Megraud F, Menard A: Identification of a genetic marker of Helicobacter pylori strains involved in gastric extranodal marginal zone B cell lymphoma of the MALT-type. Gut 2004, 53:931-937.

39. Raymond J, Thiberge JM, Chevalier C, Kalach N, Bergeret M, Labigne A, Dauga C: Genetic and transmission analysis of Helicobacter pylori strains within a family. Emerg Infect Dis 2004, 10:1816-1821.

40. Ewing B, Green P: Base-calling of automated sequencer traces using phred. II. Error probabilities. Genome Res 1998, 8:186-194.

41. Gordon D, Abajian C, Green P: Consed: a graphical tool for sequence finishing. Genome Res 1998, 8:195-202.

42. Gordon D, Desmarais C, Green P: Automated finishing with autofinish. Genome Res 2001, 11:614-625.

43. Bocs S, Cruveiller S, Vallenet D, Nuel G, Medigue C: AMIGene: Annotation of Mlcrobial Genes. Nucleic Acids Res 2003, 31:3723-3726.

doi: 10.1186/1471-2164-11-368

Cite this article as: Thiberge et al. From array-based hybridization of Helicobacter pylori isolates to the complete genome sequence of an isolate associated with MALT lymphoma BMC Genomics 2010, 11:368 